\title{
THE ELECTROCARDIOGRAM IN ASPHYXIAL AND IN EMBOLIC ACUTE COR PULMONALE
}

\author{
BY \\ F. I. CAIRD* AND C. A. STANFIELD $\dagger$ \\ From the Department of Medicine, Postgraduate Medical School of London and Hammersmith Hospital
}

Received September 15, 1961

Acute respiratory failure with alveolar under-ventilation is often due to obstruction to the airways occurring in acute exacerbations of chronic bronchitis and in severe asthma. The consequent hypoxæmia must lead to acute elevation of the pulmonary arterial pressure (Motley et al., 1948; Fishman et al., 1952), but the severity of the illness is such that this has only infrequently been demonstrated (Lenègre, 1950; Lovejoy et al., 1954). This form of acute cor pulmonale may be termed "acute asphyxial cor pulmonale" to distinguish it from that due to pulmonary embolism.

The signs of acute respiratory failure and acute asphyxial cor pulmonale include cyanosis, tachycardia, sweating, hypotension, and gallop rhythm (Westlake et al., 1955; Sieker and Hickam, 1956). The onset is frequently sudden, and often an electrocardiogram is taken to exclude pulmonary embolism or myocardial infarction. Little attention has been paid to the cardiogram in this form of acute cor pulmonale although Mack et al. (1950) and Turiaf (Turiaf and Thin, 1954; Turiaf and Blanchon, 1954; and Georges et al., 1957) have emphasized its similarity to that of pulmonary embolism.

The purpose of the present investigation is to study the electrocardiogram in acute asphyxial cor pulmonale and to compare it with that in acute embolic cor pulmonale.

\section{MATERIAL AND METHODS}

A study was made of the case records of all patients who came to necropsy at Hammersmith Hospital between January 1, 1959 and March 31, 1961 with the diagnosis of chronic bronchitis, emphysema, asthma, or pulmonary embolism or infarction, irrespective of any other diagnosis recorded. The diagnosis of acute respiratory failure was made when a rapidly deteriorating clinical state characterized by dyspnœa, increased sputum, widespread pulmonary signs, cyanosis, tachycardia (heart rate of 100 a minute or more), altered consciousness (and in some cases, hypotension and muscular twitching) occurred in a patient with chronic bronchitis, emphysema, or asthma. The diagnosis was confirmed by the finding at necropsy of an adequate cause for acute respiratory failure, such as severe obstruction to the airways by widespread purulent bronchitis or mucus plugging of the bronchi, or extensive bronchopneumonia, and no other condition likely to have given rise to the clinical episode in question. In eleven patients an adequate electrocardiogram had been taken during an episode of acute respiratory failure. Eight of the eleven died within a week of the electrocardiogram studied.

In twelve patients with pulmonary embolism or infarction post mortem, a cardiogram had been recorded during an episode clinically characteristic of pulmonary embolism. Four of

* Present address: Radcliffe Infirmary, Oxford.

$\uparrow$ This work was carried out during the tenure of an Advanced Research Fellowship of the American Heart Association. 


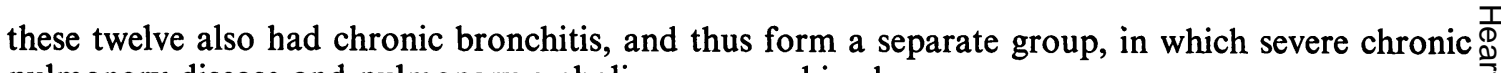
pulmonary disease and pulmonary embolism are combined.

The electrocardiographic criteria and definitions used are given below. The mean frontal plane $\stackrel{c}{\Rightarrow}$

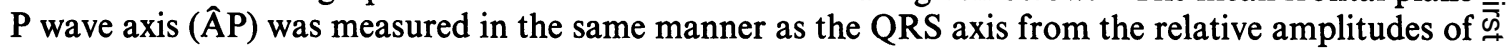
the $P$ wave in the standard leads, by the application of Einthoven's triangle. Calculation is made? easier if $1 \mathrm{~mm}$. of $P$ wave amplitude is equated, in whichever diagram is used, with 5 or $10 \mathrm{~mm}$. of $\frac{\bar{\sigma}}{\bar{D}}$ QRS amplitude, according to convenience. In this study, the diagram of Carter et al. (1919) was $\frac{\widetilde{\Phi}}{\nabla}$ employed.

Electrocardiographic Sign
$P$ waves
P wave axis (ÂP)
Right atrial P wave
QRS pattern
Standard leads
Q wave
S wave
Pracordial leads
Rs
rs
rS
S-T segment
$T$ waves

Definition
Mean frontal plane P wave axis
Pointed P wave of amplitude $2 \cdot 5 \mathrm{~mm}$.
or more in lead II, III, or aVF
Amplitude $2 \mathrm{~mm}$. or more
Amplitude equal to or greater than
corresponding $\mathbf{R}$ wave
$\mathbf{R}$ greater than $\mathrm{S}$
$\mathbf{R}$ equal to $\mathrm{S}$
$\mathbf{S}$ greater than $\mathbf{R}$
Depression or elevation of $1 \mathrm{~mm}$.
or more
Classified as upright, flat,
biphasic, or inverted

\section{RESULTS}

Acute Respiratory Failure. Table I shows the clinical and pathological data from the eleven patients with acute respiratory failure. Nine patients had chronic bronchitis, one asthma, and one a post-traumatic "frozen" hemithorax. Two had had a pulmonary lobectomy for bronchial carcinoma, and one had an untreated lung cancer.

The right ventricle was $5 \mathrm{~mm}$. or more thick in the outflow tract in all but two, and the right atrium was abnormal in most. Three had left ventricular hypertrophy. The degree of coronary arterial disease was variable, but was usually slight, and the myocardium was normal in all but one. The degree of emphysema varied greatly.

Table II shows the electrocardiographic findings. All eleven patients were in sinus rhythm at the time of their episode of acute respiratory failure. The $\mathrm{P}$ wave axis was $+70^{\circ}$ or more in all but one, and $+90^{\circ}$ or more in five. A sharply pointed $\mathrm{P}$ wave indicating right atrial enlargement was present in four. One patient had complete right bundle-branch block, and his electrocardiogram will not be considered further. Significant $Q$ waves were present in lead $I$ in two patients, but were $\triangle$ never seen in lead III. S waves were present in six, of whom two had S waves in lead I alone, three $\omega$ in leads I and III, one in leads II and III, and one in all three standard leads. A dominant R wave was seen in lead aVR in five. In the præcordial leads there was an rs or rS pattern in lead V5 in $\stackrel{O}{工}$

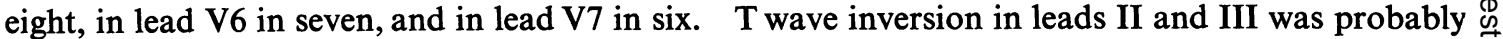
attributable to digitalis in Case 1 (Fig. 1); in no other patient was the T wave inverted in lead III, 0 but one showed an inverted $\mathrm{T}$ wave in lead I (Case 4, Fig. 2). The S-T segments were elevated in the right præcordial leads in six. The $\mathrm{T}$ waves were inverted in leads $\mathrm{V} 2$ and $\mathrm{V} 3$ in only two.

Fig. 3 shows the reversion towards normal of the electrocardiogram after two episodes of extre- $\frac{\mathbb{\nabla}}{\stackrel{0}{\perp}}$ mely severe asthma in a middle-aged woman, whose case is not included in the main series. The P 
TABLE I

Clinical and Pathological Data in 11 Cases of Acute Respiratory Fallure

\begin{tabular}{|c|c|c|c|c|c|c|c|c|c|c|}
\hline \multirow{3}{*}{$\begin{array}{l}\text { Case } \\
\text { No. }\end{array}$} & \multirow{3}{*}{ Sex } & \multirow{3}{*}{ Age } & \multirow{3}{*}{ Clinical diagnosis } & \multicolumn{6}{|c|}{ Cardiac pathology } & \multirow{3}{*}{ Pulmonary pathology } \\
\hline & & & & \multirow{2}{*}{ R.A. } & \multirow{2}{*}{ R.V.* } & \multicolumn{2}{|c|}{ Chambers } & \multirow{2}{*}{$\begin{array}{l}\text { Coronary } \\
\text { arterial } \\
\text { disease }\end{array}$} & \multirow{2}{*}{ Myocardium } & \\
\hline & & & & & & L.A. & L.V.* & & & \\
\hline 1 & $\mathbf{F}$ & 69 & $\begin{array}{l}\text { Chronic bronchitis; } \\
\text { left upper lobe } \\
\text { tuberculosis }\end{array}$ & HD & 10 & $\mathbf{N}$ & 15 & Slight & Normal & $\begin{array}{l}\text { Purulent bronchitis; old cavi- } \\
\text { tation left upper lobe; much } \\
\text { pleural thickening; no emphy- } \\
\text { sema. (Secondary amyloido- } \\
\text { sis). }\end{array}$ \\
\hline 2 & $\mathbf{M}$ & 70 & $\begin{array}{l}\text { Chronic bronchitis; } \\
\text { tracheostomy }\end{array}$ & HD & 8 & $\mathbf{N}$ & 18 & Moderate & Normal & $\begin{array}{l}\text { Hæmorrhagic tracheobronchitis; } \\
\text { confluent bronchopneumonia; } \\
\text { abscesses both lower lobes; } \\
\text { moderate emphysema. }\end{array}$ \\
\hline 3 & $\mathbf{M}$ & 63 & Chronic bronchitis & $\mathbf{D}$ & 7 & $\mathbf{N}$ & 17 & Slight & Normal & $\begin{array}{l}\text { Purulent bronchitis; broncho- } \\
\text { pneumonia; slight emphysema }\end{array}$ \\
\hline 4 & $\mathbf{F}$ & 49 & $\begin{array}{l}\text { Asthma; tracheostomy; } \\
\text { IPPR }\end{array}$ & D & 5 & $\mathbf{N}$ & 14 & Slight & Normal & $\begin{array}{l}\text { Gross mucus plugging of bronchi } \\
\text { in all areas }\end{array}$ \\
\hline 5 & $\mathbf{F}$ & 60 & Chronic bronchitis & HD & 7 & 一 & 13 & None & Normal & $\begin{array}{l}\text { Much bronchial mucus; severe } \\
\text { centrilobular emphysema }\end{array}$ \\
\hline 6 & $\mathbf{F}$ & 58 & Chronic bronchitis & 一 & 9 & $\mathbf{N}$ & $\mathbf{N}$ & Slight & Normal & Purulent bronchitis; no emphy- \\
\hline 7 & $\mathbf{M}$ & 70 & Chronic bronchitis & $\mathbf{D}$ & 6 & $\mathbf{N}$ & 15 & Slight & Normal & Purulent bronchitis; widespread \\
\hline 8 & $\mathbf{M}$ & 60 & $\begin{array}{l}\text { Carcinoma bronchus; } \\
\text { left upper lobectomy } \\
\text { and radiotherapy }\end{array}$ & D & 5 & $\mathbf{N}$ & 15 & None & Normal & $\begin{array}{l}\text { Bronchopneumonia; centrilo- } \\
\text { bular emphysema in R lung; left } \\
\text { upper lobectomy; no recurrence }\end{array}$ \\
\hline 9 & $\mathbf{M}$ & 63 & $\begin{array}{l}\text { L. "frozen chest"; } \\
\text { carcinoma bronchus }\end{array}$ & $\mathbf{N}$ & 3 & $\mathbf{N}$ & 14 & Slight & Normal & $\begin{array}{l}\text { L.empyema with calcified pleura; } \\
\text { fibrosis left upper lobe and } \\
\text { right lower lobe; consolidation } \\
\text { right upper and middle lobes; } \\
\text { multiple secondaries }\end{array}$ \\
\hline 10 & $\mathbf{M}$ & 61 & $\begin{array}{l}\text { Chronic bronchitis; } \\
\text { left lower lobectomy } \\
\text { for carcinoma }\end{array}$ & $\mathbf{N}$ & 3 & $\mathbf{N}$ & 15 & Moderate & Normal & $\begin{array}{l}\text { Left lower lobectomy; gross } \\
\text { mucus plugging of all bronchi; } \\
\text { no emphysema; no recurrence }\end{array}$ \\
\hline 11 & $\mathbf{M}$ & 61 & $\begin{array}{l}\text { Chronic bronchitis; } \\
\text { morphine }\end{array}$ & $\mathbf{D}$ & 7 & 一 & 17 & Slight & $\begin{array}{l}\text { Fibrosis } \\
\text { posterior } \\
\text { L.V. }\end{array}$ & $\begin{array}{l}\text { Purulent bronchitis; severe } \\
\text { bullous emphysema }\end{array}$ \\
\hline
\end{tabular}
hypertrophied. $\mathbf{D}=$ dilated. L.A =left atrium. L.V. $=$ left ventricle.

* Thickness (mm.) in outflow tract.

$\uparrow$ Greatest thickness (mm.).

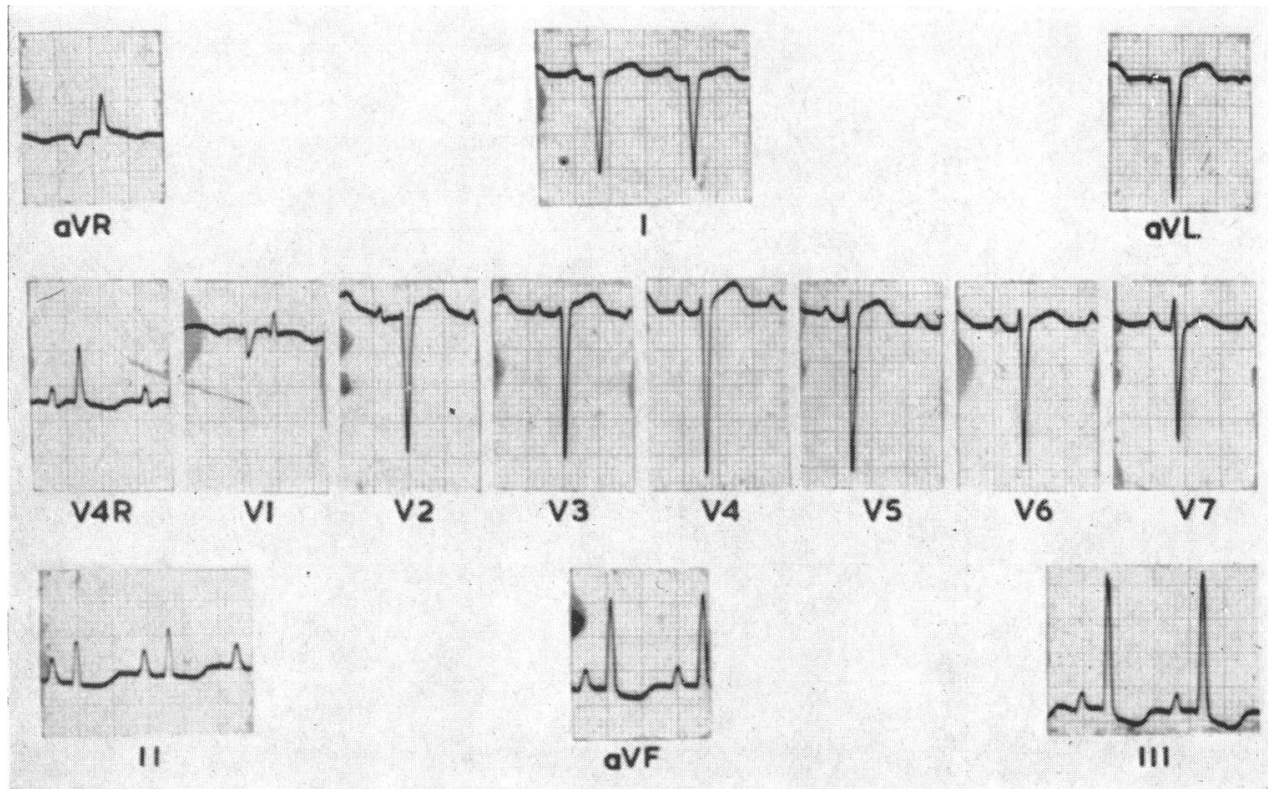

FIG. 1.-Electrocardiogram of Case 1 (asphyxial cor pulmonale) showing ÂP $+70^{\circ}$, right atrial $P$ wave, $S$ in lead I, dominant $R$ in aVR, rS pattern in leads V5 to V7, S-T segment depression, and $\mathrm{T}$ wave inversion in leads II and III (possibly attributable to digitalis), and upright $\mathrm{T}$ waves in leads V2 to V7. 


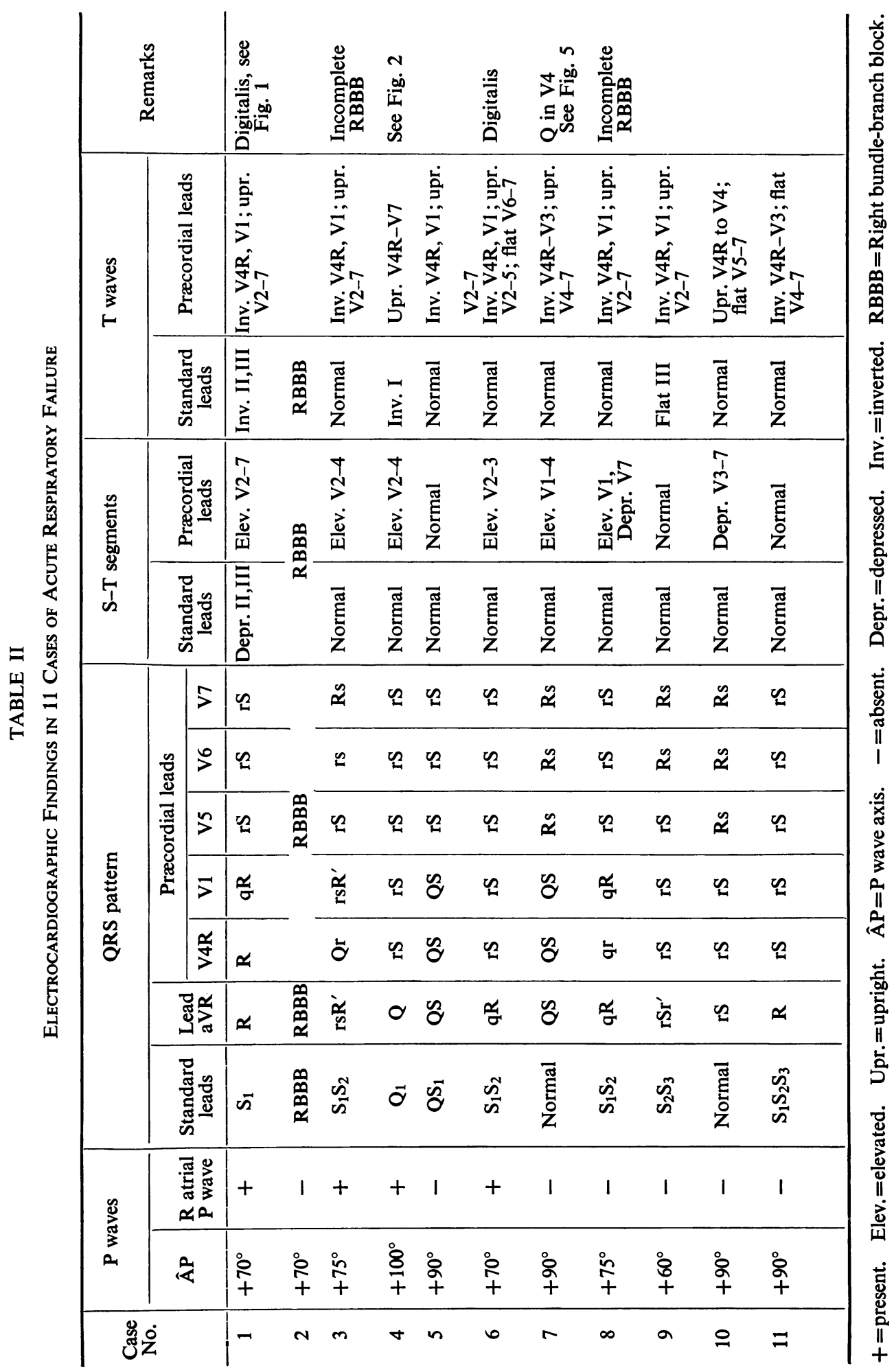


TABLE III

Clinical and Pathological Data in 12 Cases of Pulmonary Embolism

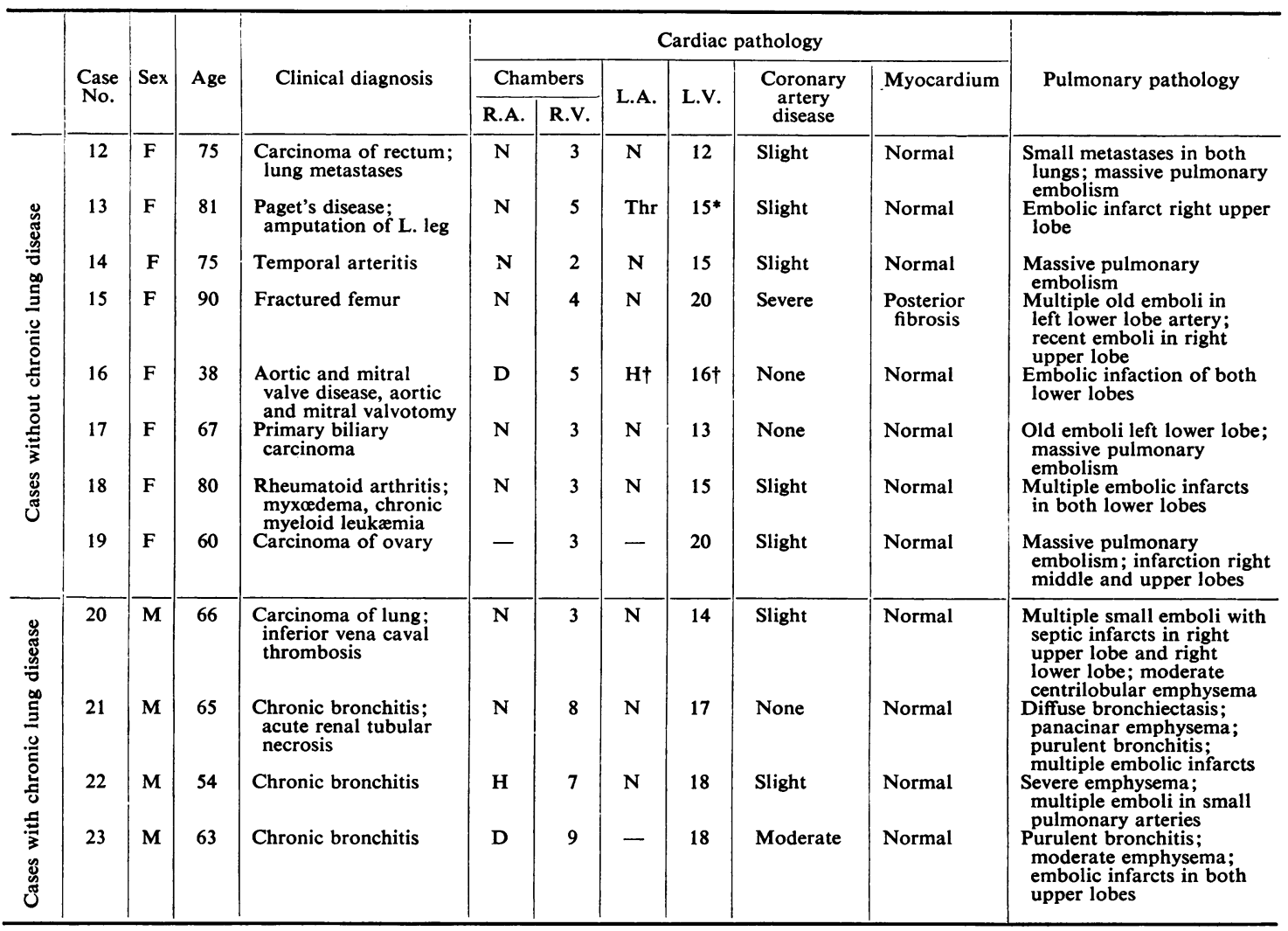

Symbols as in Table I. $\mathrm{Thr}=$ thrombus.

* Slight mitral stenosis; acute bacterial endocarditis of aortic valve.

$\uparrow$ Mitral and aortic stenosis relieved.

waves diminish in amplitude in leads II and III, and the $\mathrm{P}$ wave axis shifts to the left. The rS pattern disappears from the left præcordial leads. The $\mathrm{T}$ waves are upright.

The usual electrocardiographic pattern in acute respiratory failure consists of sinus tachycardia with a $\mathrm{P}$ wave axis of $+70^{\circ}$ or more, an rS pattern in leads V5 to V7, and upright $\mathrm{T}$ waves in leads V2 to V7 (Fig. 1-3). A P wave axis of $+90^{\circ}$ or more (Fig. 2), deep S waves in leads I and II, and dominant $\mathrm{R}$ waves in lead VR are often seen (Fig. 1). These changes may be transient (Fig. 3). $Q$ waves were not seen in lead III, and inversion of $T$ in lead III was infrequent.

Pulmonary Embolism. Table III shows the clinical and pathological findings in the twelve patients with pulmonary embolism, including the four (Cases 20 to 23) in whom this occurred in the presence of severe chronic pulmonary disease. The heart was anatomically abnormal in seven patients.

Of the eight patients without chronic pulmonary disease, three showed atrial fibrillation (Table IV). The $\mathrm{P}$ wave axis was $+70^{\circ}$ or more in three of the five with sinus rhythm. None showed a right atrial $P$ wave. One patient had left bundle-branch block, and her electrocardiogram will not be considered further. Significant Q waves were present in lead III in two, and S waves in the standard leads in four. Two patients had an rs pattern in lead V5, and one in lead V6, but none in lead V7. S-T segment depression was seen in the standard leads in five, and in the left præcordial leads in six. The T waves were inverted in one or more standard leads in five, and in lead V3 in three.

The pattern seen in the four patients with both chronic pulmonary disease and pulmonary embolism is of great interest. In Case 22 there is doubt about the relationship in time between the 


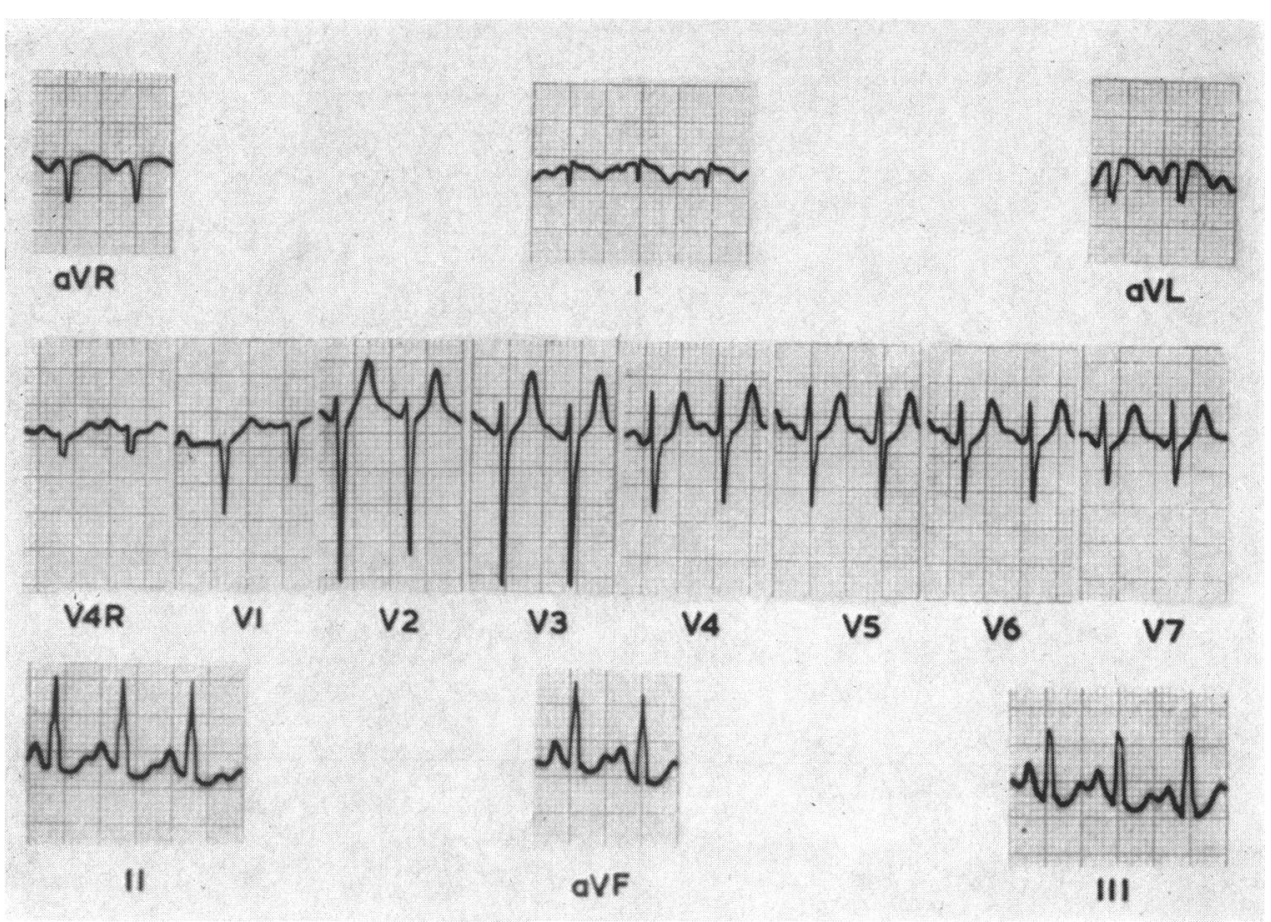

FIG. 2.-Electrocardiogram of Case 4 (asphyxial cor pulmonale), showing ÂP $+100^{\circ}$, right atrial $\mathbf{P}$ wave, $\mathbf{Q}$ in lead $\mathrm{I}, \mathrm{rS}$ in all præcordial leads, and $\mathrm{T}$ inverted in lead $\mathrm{I}$ but upright in all præcordial leads.

electrocardiogram studied and the many small pulmonary emboli found at necropsy; he had chronic hypoxæmia and hypercapnia, and repeated episodes of severe dyspnœa and tachycardia. All the three patients with sinus rhythm showed right atrial $P$ waves. One had $S$ waves in all three standard leads (Fig. 4), another $S$ in lead I. Two had dominant $R$ waves in lead aVR. All four had an rs or rS pattern in lead V5 (Fig. 4), and two an rS pattern in leads V6 and V7. The T wave was inverted in lead III in one, and in leads V3 and V4 in one.

\section{Discussion}

Comparison between the electrocardiogram of acute asphyxial cor pulmonale and that of pulmonary embolism can be made if our data on the electrocardiogram in pulmonary embolism are amplified by reference to the substantial literature on the subject (McGinn and White, 1935; Phillips and Levine, 1950; Zuckerman et al., 1950; Laham and Gerbaux, 1951; Soulié et al., 1951; Eliaser and Giansiracusa, 1952; and Cutforth and Oram, 1958).

Cardiac Rhythm. None of the patients with acute asphyxial cor pulmonale showed an arrhythmia during the episode in question, although Case 11 had a variety of arrhythmias on other occasions. Thus, although supraventricular arrhythmias are not rare in chronic pulmonary disease, their presence should suggest a complication other than acute respiratory failure. Atrial fibrillation (Sagall et al., 1954; Short, 1952) and other arrhythmias (Zuckerman et al., 1950; Laham and Gerbaux, 1951) are of course not infrequently precipitated by pulmonary embolism.

$P$ Wave Changes. A shift to the right in the $P$ wave axis is characteristic of the electrocardiogram of patients with airways obstruction (Novelo, 1945; Spodick, 1959; Caird and Wilcken, 1961). Table III shows that the same is true of acute asphyxial cor pulmonale, the most striking example being Case 4, with a $\mathrm{P}$ wave axis of $+100^{\circ}$ (Fig. 2). Turiaf and Thin (1954) and George, 
THE ELECTROCARDIOGRAM IN COR PULMONALE

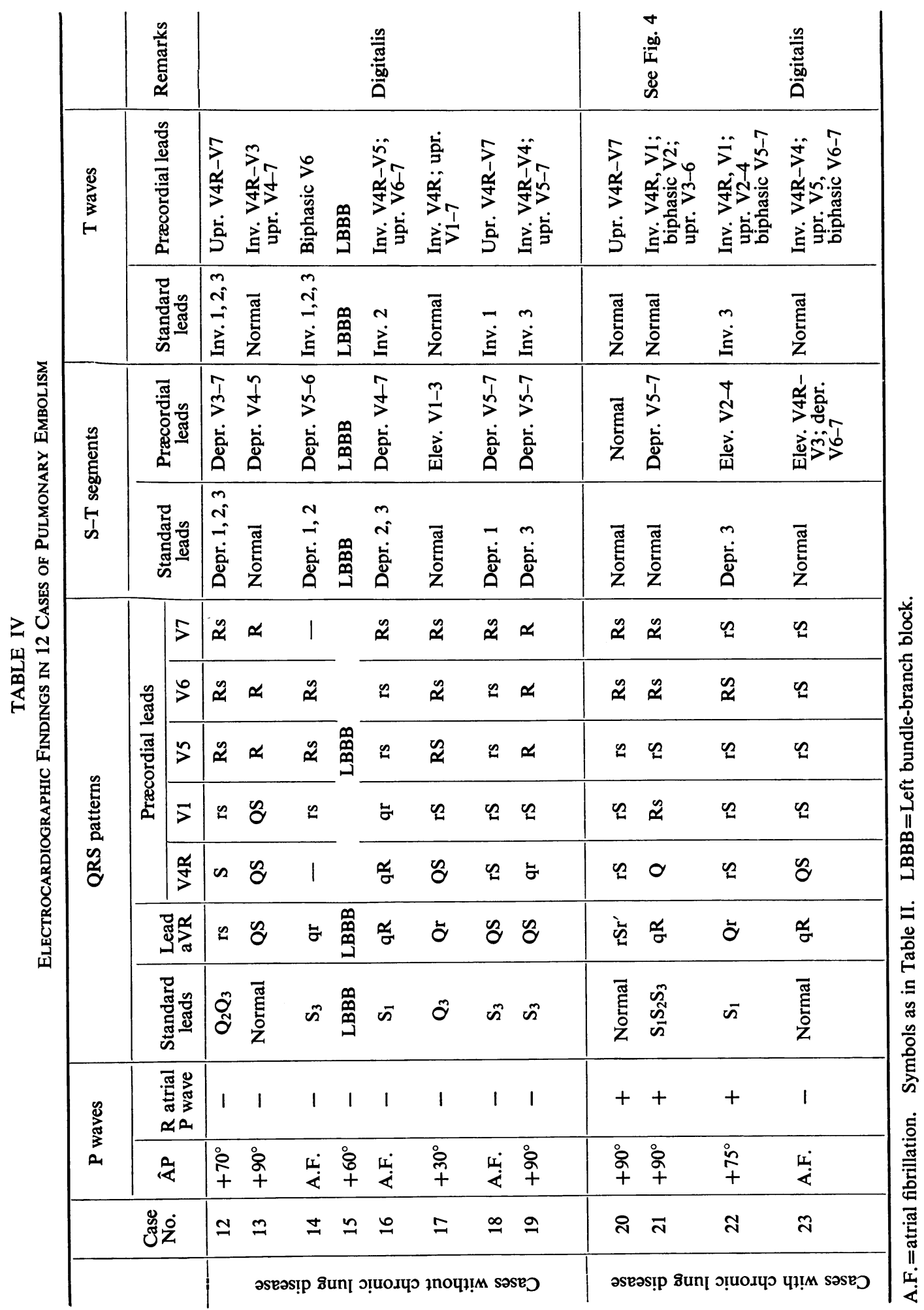



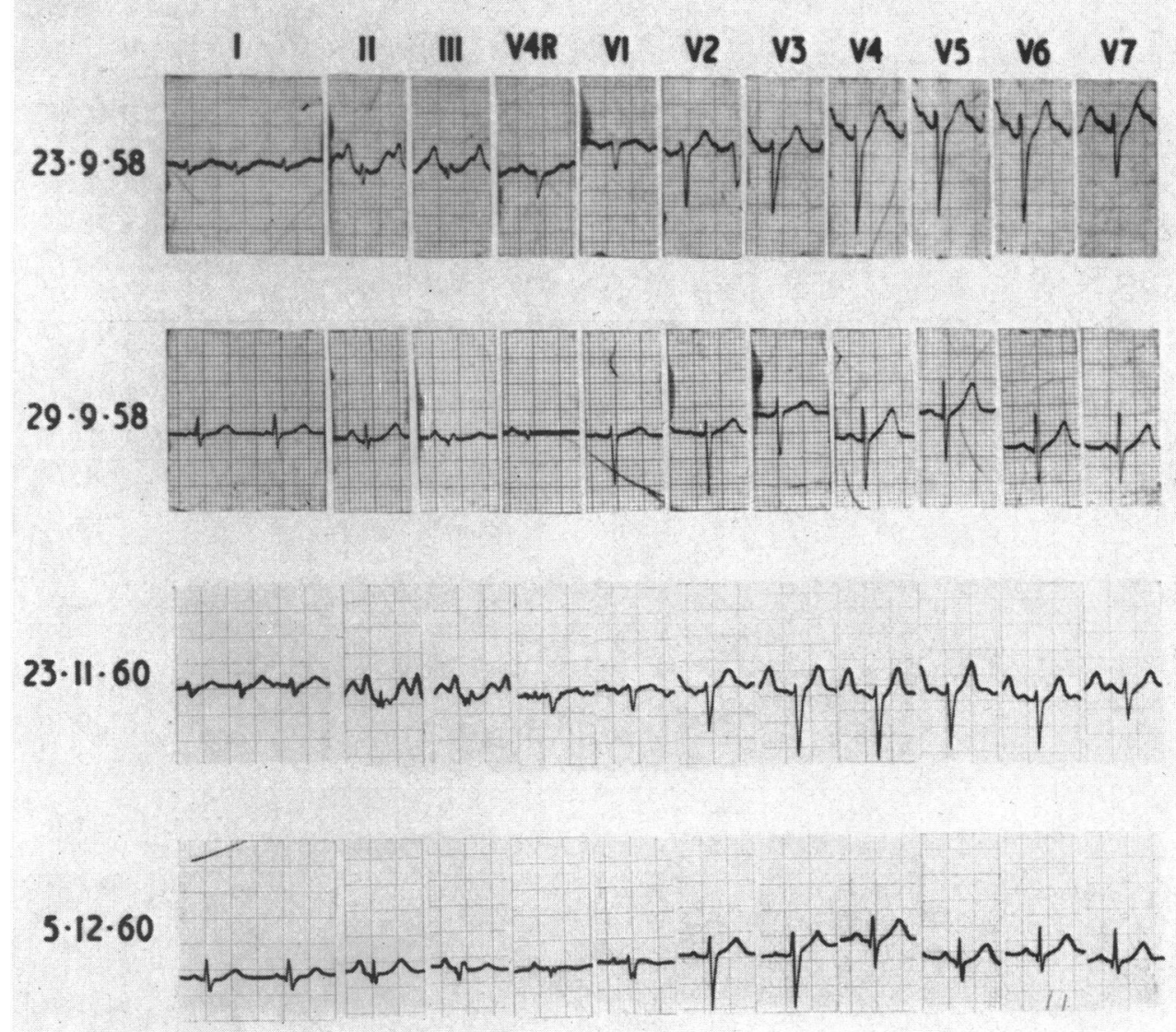

Fig. 3.-Electrocardiograms of a 58-year-old woman with asthma. Records of 23/9/58 and 23/11/60 taken during episodes of severe status asthmaticus show tall $\mathrm{P}$ waves and extreme clockwise rotation ( $\mathrm{rS}$ in leads V5 to V7). Records of 29/9/58 and 5/12/60 taken during remissions show reversion towards normal.

et al. (1957) record similar findings in status asthmaticus. A shift in $\mathrm{P}$ wave axis is usually stated to be rare in pulmonary embolism (Laham and Gerbaux, 1951), but an axis of $+90^{\circ}$ can certainly occur in pulmonary embolism in the absence of chronic pulmonary disease (Delanoë, 1951; Eliaser and Giansiracusa, 1952, Case 3; Cases 13 and 19 in this series). Too much reliance cannot therefore be placed on this sign for the exclusion of pulmonary embolism, although a $P$ wave axis of less than $+60^{\circ}$ should be regarded as evidence against a cardiographic diagnosis of acute asphyxial cor pulmonale.

A right atrial $\mathbf{P}$ wave is considered rare in pulmonary embolism, though there were six examples among Cutforth and Oram's (1958) fifty patients. It was found in four of our eleven patients with acute asphyxial cor pulmonale (Fig. 1) and in three of the four with pulmonary embolism complicating chronic pulmonary disease (Fig. 4). Thus a right atrial $P$ curve should suggest chronic pulmonary disease rather than pulmonary embolism. It cannot assist in the differentiation of acute asphyxial from acute embolic cor pulmonale in patients with chronic pulmonary disease.

QRS Patterns. The characteristic alteration in QRS pattern in the standard leads in acute embolic cor pulmonale consists of the development of an S wave in lead I and sometimes lead II 


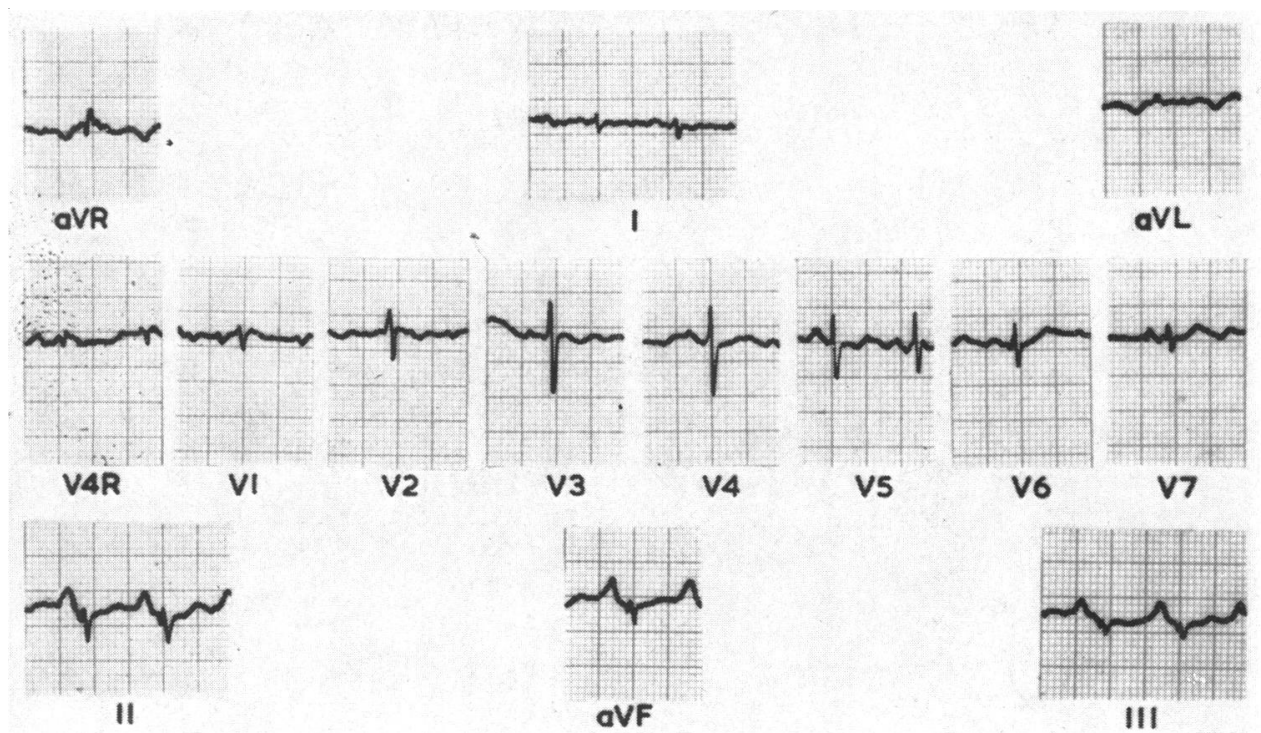

FIG. 4.-Electrocardiogram of Case 21, showing ÂP $+90^{\circ}$, right atrial $\mathrm{P}$ wave, $\mathrm{S}$ waves in all standard leads, dominant $R$ in lead aVR, $r S$ in lead V5, and biphasic T in lead V2. (Necropsy examination showed multiple embolic pulmonary infarcts in addition to severe emphysema.)

and of a $Q$ wave in lead III (McGinn and White, 1935). Mack et al. (1950) noted similar changes in respiratory failure. Deep $S$ waves were seen in lead I in six of our eleven patients with acute asphyxial cor pulmonale, and in lead II in four. Q waves occurred in lead I in two, but not in lead III in any case. The presence of $Q$ in lead III may be evidence against a diagnosis of acute asphyxial cor pulmonale.

A dominant $R$ wave may develop in lead aVR in pulmonary embolism (Friedberg, 1956). This sign was present in five of the eleven patients with acute respiratory failure and two of the four with both pulmonary embolism and chronic pulmonary disease.

In pulmonary embolism there is frequently a shift to the left in the transition zone in the præcordial leads (Phillips and Levine, 1950; Laham and Gerbaux, 1951; Soulié et al., 1951; Eliaser and Giansiracusa, 1952; Cutforth and Oram, 1958). The electrocardiograms illustrated by these authors suggest that the S wave rarely becomes dominant in leads V5 or V6. Indeed two of the cases showing clockwise rotation of this degree had in fact not pulmonary embolism but respiratory failure (Phillips and Levine, 1950, Case 7; Laham and Gerbaux, 1951, Case 14). Of our ten patients with acute asphyxial cor pulmonale and normal QRS complexes, there was an rs or rS pattern in lead V5 in eight, in lead V6 in seven, and in lead V7 in six. An rS pattern in lead V5 was seen in three of the four patients with pulmonary embolism and chronic pulmonary disease, and in leads V6 and V7 in two patients. Extreme "clockwise rotation" would thus seem to be one of the most frequent electrocardiographic signs of acute asphyxial cor pulmonale, though there may on occasion be no clockwise rotation at all, as Fig. 5 shows. It will not, however, serve to exclude pulmonary embolism in patients with chronic pulmonary disease. In both instances there is an exaggeration of the clockwise rotation with an $\mathrm{rS}$ pattern in lead V5, which is often the first and only sign of right ventricular hypertrophy in chronic pulmonary disease (Carouso et al., 1951). This exaggeration may be due to dilatation of the right ventricle (Zuckerman et al., 1950), or to positional changes associated with an increase in lung volumes consequent on obstruction to the airways, or to both. Studies of the electrocardiogram in acute respiratory failure in conditions not accompanied by obstruction to the airways might clarify this point. 
Fig. 3 illustrates the regression of extreme clockwise rotation on recovery from acute respiratory failure. Thus the electrocardiographic signs tend to be transient.

Conduction Defects. Complete or incomplete right bundle-branch block is seen on occasion in pulmonary embolism (Soulié et al., 1951; Cutforth and Oram, 1958). Complete right bundlebranch block was present in one and incomplete in two of our eleven patients with acute asphyxial cor pulmonale.

$S-T$ Segment and $T$ Wave Changes. In pulmonary embolism the standard leads may show depression of the S-T segment with upright T waves, giving rise to the "staircase pattern" (McGinn and White, 1935). In the præcordial leads there may be depression on the left (Soulié et al., 1951; Laham and Gerbaux, 1951; Cutforth and Oram, 1958), and elevation on the right (Laham and Gerbaux, 1951). S-T segment depression was seen in lead I in only one case of acute asphyxial cor pulmonale, and then was probably attributable to digitalis (Fig. 1). Changes in the præcordial leads were more frequent, since elevation of the S-T segment occurred in the right præcordial leads in six cases (Fig. 1 and 2).

T wave inversion in lead III and over the right præcordium is characteristic of acute embolic cor pulmonale. Only one of the eleven patients with acute asphyxial cor pulmonale showed $\mathrm{T}$ wave inversion in lead III (and this was probably due to digitalis) (Fig. 1), and only two patients showed inversion in leads V2 or V3 (Fig. 5). Of the four patients with pulmonary embolism and chronic 
pulmonary disease one had $T$ wave inversion in lead V3. Thus $T$ wave inversion in the right præcordial leads is rare in acute asphyxial cor pulmonale. Its presence may be used as evidence against that electrocardiographic diagnosis, but it is often absent also when pulmonary embolism complicates chronic pulmonary disease (Fig. 4).

\section{SUMMARY}

A comparison has been made of the electrocardiogram of 11 patients with acute respiratory failure, 8 with pulmonary embolism, and 4 with pulmonary embolism complicating chronic pulmonary disease.

In acute respiratory failure the electrocardiogram characteristically shows sinus tachycardia, a $P$ wave axis of $+70^{\circ}$ or more, extreme "clockwise rotation" (rS pattern in leads V5 to V7), and upright $\mathrm{T}$ waves in leads III and V2 to V7. A right atrial $\mathrm{P}$ wave is frequent.

In acute respiratory failure, in contrast with pulmonary embolism, there is only rarely a $Q$ wave in lead III, S-T segment depression in leads I and II, or T wave inversion in lead III or over the right præcordium.

A dominant $\mathrm{R}$ wave in lead aVR and deep S waves in leads I and II are seen in both conditions, and in both the electrocardiographic signs tend to be transient.

When pulmonary embolism complicates chronic pulmonary disease, the electrocardiogram often shows changes resembling those of acute respiratory failure, rather than those of pulmonary embolism.

The term "acute asphyxial cor pulmonale" is proposed for the cardiovascular manifestations of acute respiratory failure.

Our thanks are due to Drs. J. F. Goodwin and N. B. Pride for their advice and criticism; to Professor C. V. Harrison for access to the post-mortem records; and to Mrs. Carole Bennett for the illustrations.

\section{REFERENCES}

Caird, F. I., and Wilcken, D. E. L. (1961). Amer. J. Cardiol. (in press.)

Carouso, G., Maurice, P., Scébat, L., and Lenègre, J. (1951). Arch. Mal. Cour., 44, 769.

Carter, E. P., Richter, C. P., and Greene, G. H. (1919). Bull. Johns Hopk. Hosp., 30, 162.

Cutforth, R. H., and Oram, S. (1958). Brit. Heart J., 20, 41.

Delanoë, G. (1951). Arch. Mal. Coeur, 44, 1029.

Eliaser, M., and Giansiracusa, F. (1952). Amer. Heart J., 43, 533.

Fishman, A. P., McClement, J., Himmelstein, A., and Cournand, A. (1952). J. clin. Invest., $31,770$.

Friedberg, C. K. (1956). Diseases of the Heart. W. B. Saunders, Philadelphia, p. 961.

Georges, R., Sauvan, R., Blanchon, P., and Turiaf, J. (1957). Arch. Mal. Coeur., 50, 415.

Laham, J., and Gerbaux, A. (1951). Arch. Mal. Coeur., 44, 328.

Lenègre, J. (1950). Bull. Mém. Soc. Méd. Hôp. Paris, 66, 1095.

Lovejoy, F. W., Yu, P. N. G., Nye, R. E., Joos, H. A., and Simpson, J. H. (1954). Amer. J. Med., $16,4$.

Mack, I., Harris, R., and Katz, L. N. (1950). Amer. Heart J., 39, 664.

McGinn, S., and White, P. D. (1935). J. Amer. med. Ass., 104, 1473.

Motley, H. L., Cournand, A., Werko, L., Himmelstein, A., and Dresdale, D. (1947). Amer. J. Physiol, $150,315$.

Novelo, S. (1945). Arch. Inst. Cardiol. Mexico, 15, 179.

Phillips, E., and Levine, H. D. (1950). Amer. Heart J., 39, 205.

Sagall, E. L., Bornstein, J., and Wolff, L. (1945). Arch. intern. Med., 76, 234.

Short, D. S. (1952). Brit. med. J., 1, 790.

Sieker, H. O., and Hickam, J. B. (1956). Medicine (Baltimore), 35, 389.

Soulié, P., Tricot, L., and Verdun di Cantogno, L. (1951). Arch. Mal. Cour, 44, 876.

Spodick, D. H. (1959). Circulation, 20, 1067, 10, 1073.

Turiaf, J., and Blanchon, P. (1954). Arch. Mal. Caur, 47, 499.

We and Thin, J. (1954). Sem. Hôp. Paris, 30, 687.

Westlake, E. K., Simpson, T., and Kaye, M. (1955). Quart. J. Med. N.S., 24, 155.

Zuckerman, R., Rodiguez, M. I., Sodi-Pallares, D., and Bisteni, A. (1950). Amer. Heart J., $40,805$. 